\title{
Simulation of Biogas Production from Solid Organic
}

\section{Wastes}

\author{
Ignacio Contreras-Andrade ${ }^{1}$, Jonathan Parra-Santiago ${ }^{2}$ and Carlos Alberto Guerrero-Fajardo ${ }^{3 *}$ \\ 1. Doctor Chemical Engineering, Autonomous University of Sinaloa, Culiacan Rosales 80040, México \\ 2. Chemical Engineering(C), National University of Colombia, Bogotá 11001, Colombia \\ 3. Chemical Engineering and Mechanical, National University of Colombia, Bogotá 11001, Colombia
}

\begin{abstract}
The design and building of new alternative fuel plants is an increasing necessity to replace old technology and non-renewable fossil fuels. To optimize the performance of these plants and to obtain an economically feasible production of these types of fuels, it is necessary to have a total control of each variable involved in the process of production and how these factors affect the yield of fuel production. In this paper it is proposed a model of a digester to generate gas using a Vensim software designed to generate simulations in dynamic state. This simulation was developed using differential equations to model the behavior at each stage of the process and auxiliary conditions to complement the mathematical description of the model. The main factors in the biogas production are the retention time and the methanogen mortality ratio. For retention time lower than $10 \mathrm{~h}$ the process loses effectiveness due to bacterial growth is not completed efficiently, but a high retention time involves a bigger reactor and the yield of production decreases considerably for retention time higher than $40 \mathrm{~h}$. The best yields were obtained for a mortality ratio in methanogen and acidogenic bacteria lower than 0.2 and a retention time of $30 \mathrm{~h}$ with a final production of $3.33 \mathrm{~L}$ by each kilogram of biomass.
\end{abstract}

Key words: Bio-digester, bio-digestion, gas synthesis, renewable energy.

\section{Introduction}

A recent interest in renewable energy production has produced an increase in development of new technology for renewable fuels production to replace the oil consumption [1]. It is due to the high pollution and generation of $\mathrm{CO}_{2}$ produced by fossil fuel and an increase in price of production and commercialization of these types of energy due to a constant decrease in global reserves of it [2].

The main fossil fuel sources are coal, oil and natural gas. Each one of these has a similar production ratio by year and it is increasing according to the time with a high representative fraction due to development countries such as United States and China. For another hand, due to a constant increase in energy consumption, each one of these fossil fuels has had a high increase

\footnotetext{
*Corresponding author: Carlos Alberto Guerrero Fajardo, Associated Professor/Ph.D., research fields: oils fuel, renewable fuel and catalysis. E-mail: caguerrerofa@unal.edu.co.
}

during the last years going from $340 \mathrm{EJ} / \mathrm{y}$ to $500 \mathrm{EJ} / \mathrm{y}$ between 2000 and 2012. This change was largely due to booming Chinese production and some other factors related to increase in processes production and population increase [3].

One of the main alternatives to replace fossil fuels is the biodiesel production, but this process has some disadvantage such as the production of glycerol as byproduct. In this case some alternatives to purify this byproduct to obtain another commercial product have been developed [4], but due to these processes are economically unviable it is another problem to the sustainability energy production process.

Recent alternatives to replace fossil fuels are unviable in some aspects such as economically, environmentally and ecologically due to similar reasons. However there are some alternatives analyzed to energy production in local places to supply requirements of residents of close areas such as 
bio-digester technology which is used in the production of natural gas from waste organic matter [5].

Some advantages of this process are a building and maintenance of equipment relatively easy, processing of waste material to obtain a profitable energy source and building of process plants near to the place in where energy is used [6].

This process involves the use of a great variety of bacteria which processed the waste material to biodegrade it while natural gas is produced. It is composed by two sub-processes; the first of these one consists in the conversion of solid waste in fatty acids by acidophilic bacteria, then in the second sub-process fatty acids are used by anaerobic methanogens to produce methane [7]. However, this process has some drawbacks for modeling due to multiple biological agents are used in each one of these sub-processes to obtain an economically viable process without the need to use specific bacterial species [8].

Some models and methods have been proposed to obtain results with similar results to real behavior of systems by individual compound analysis and by analysis of each step [9], but these methods have some problems to simulate real situations due to these are not taking into account the synergy between some of these factors involved in this process.

By this reason, the method of process dynamics is a good option to characterize each parameter according to the influence of the other factors to analyze the effect in the model produced by some modifications in the values of the process [10]. Some of these attempts to characterize a digester by this method were carried out by Billington [11], Hill [12-15] and Bala [16], however these models have a high stationary process character and it is great fail to model real bio-digesters.
By this reason some investigations try to change the main focus to add other characteristics that change over the time. In this way some models were developed including the factor of microbial growth by Monod kinetic method [17], and some simulations of kinetic models of production process were carried out taking into account these models with best results in similar data to real bio-digester processes [18].

The main problem with these models is the obsolescence of software used to develop the simulation. In this case DYNAMO (dynamic modeling) was a software with excellent characteristics of simulation for stationary and dynamic systems but nowadays it is really antique and it has fallen into obsolescence due to its inability to model modern complex systems. By this reason in this paper the model of Hill was adapted to be reconstructed and simulated in a new software of dynamic systems called Vensim and with the possibility to obtain the main process characteristics.

Vensim is nowadays a industrial strength simulation software for improving the performance of real systems due to it has a full set of emphasizes model quality, flexible distribution, connections to data, and to possibility to include advanced algorithms.

\section{Simulation Process}

The simulation was carried out using the equations proposed by Hill [17] and treated previously by dynamic state simulation in DYNAMO software [18]. In this case were used 5 box variables (stock) with its respective ranges and 11 auxiliary constants. In the same way equations were defined according to the range of these variables, Table 1 shows the relation between variables stock and auxiliary constants.

Table 1 Stock and auxiliary variables.

\begin{tabular}{lll}
\hline Variable & Range & Auxiliary constants \\
\hline Solids & Solid feed ratio & Solid feed/acidogenic growth rate/acidogenic consumption/bacterial \\
papulation/retention time
\end{tabular}


Differential equations were used to analyze each step in the production of natural gas by decomposition of solid waste material. In this way to model the quantity of solid waste flow in the system was used an equation which correlate the feed of solid material and the quantity of it in the reactor. It is expressed by:

$$
\frac{d S}{d t}=\frac{S_{0}-S}{\theta}-\frac{\mu M}{Y}
$$

In this expression, $d S$ is the quantity of solid waste being fed to the bio-digester in a fraction of time $d t$ as a function of:

$$
\begin{gathered}
S_{0}=\text { Quantityof solidmaterialbeingfed } \\
S=\text { Quantityof solidmaterialinthebiodigester } \\
\theta=\text { Retentiontime } \\
\mu=\text { Acidogenicgrowthratio } \\
M=\text { Acidogenicpopulationsize } \\
Y=\text { Acidogenicaverageconsumption }
\end{gathered}
$$

It is possible to identify a correlation between the quantity of solids in the process and the quantity of solids being fed taking into account the consumption of it carried out by the acidogenic bacteria.

In the same way a similar expression is obtained to describe the quantity of fatty acids available for methanogen bacteria. For this process is observed a similar behavior due to the quantity of fatty acids in the bio-digester is a function of fatty acids present in the feed and fatty acids produced in the reactor by acidogenic bacteria, taking into account in this case the consumption of it carried out by the methanogen bacteria. It is expressed by:

$$
\frac{d A C}{d t}=\frac{A C_{0}-A C}{\theta}+\mu M Y_{a}-\frac{\mu_{C} M_{C}}{Y_{C}}
$$

where,

$$
\begin{gathered}
A C_{0}=\text { Quantityoffattyacidsinthefeed } \\
A C=\text { Quantityoffattyacidsinthebiodigester } \\
Y_{a}=\text { Averageproductionoffattyacids } \\
\mu_{C}=\text { Methanogengrowgthratio } \\
M_{C}=\text { Methanogenpopulationsize } \\
Y_{C}=\text { Methanogenaverageconsumption }
\end{gathered}
$$

At this point were developed the first simulations and by that reason some errors were produced. By this reason it is necessary to take into account the necessity of include another factor to correct the quantity of acidogen and methanogen bacteria in each moment of the process [19]. By this reason it is necessary to include a model to simulate the bacterial growth in each stage, in this case was selected the Monod model according to literature data [16-18]. According to it, the expressions to describe acidogen and methanogen bacteria respectively are:

$$
\begin{gathered}
\frac{d M}{d t}=\left(\mu-k_{d}-\frac{1}{\theta}\right) M \\
\frac{d M_{C}}{d t}=\left(\mu_{C}-k_{d C}-\frac{1}{\theta}\right) M_{C}
\end{gathered}
$$

where,

$$
\begin{gathered}
k_{d}=\text { Acidogenmortalityratio } \\
k_{d C}=\text { Methanogenmortalityratio }
\end{gathered}
$$

Finally, the quantity of biogas produced is a direct function of the quantity of methanogen in the bio-digester, by this reason it is necessary to add a proportionality constant to this factor to obtain a correlation of the change in the production as a function of the time. It is expressed by:

$$
\frac{d P}{d t}=\beta \mu_{C} M_{C}
$$

To condense the information about the process, variables used and the dependence of each one of these, Fig. 1 shows the schematic representation of simulation process carried out in Vensim. In this figure we can see the five main variables used to structure the process and around each of these are located each one of the parameters used to manipulate the average of the system. In this case dashed arrows represent the influence of a parameter and the thick arrows represent the possibility to change a value within an established range.

\section{Analysis of Results}

By this simulation in Vensim was possible determinate the existence of two main parameters in the production of gas in a bio-digester system. Due to the retention time is the main factor to determine the 


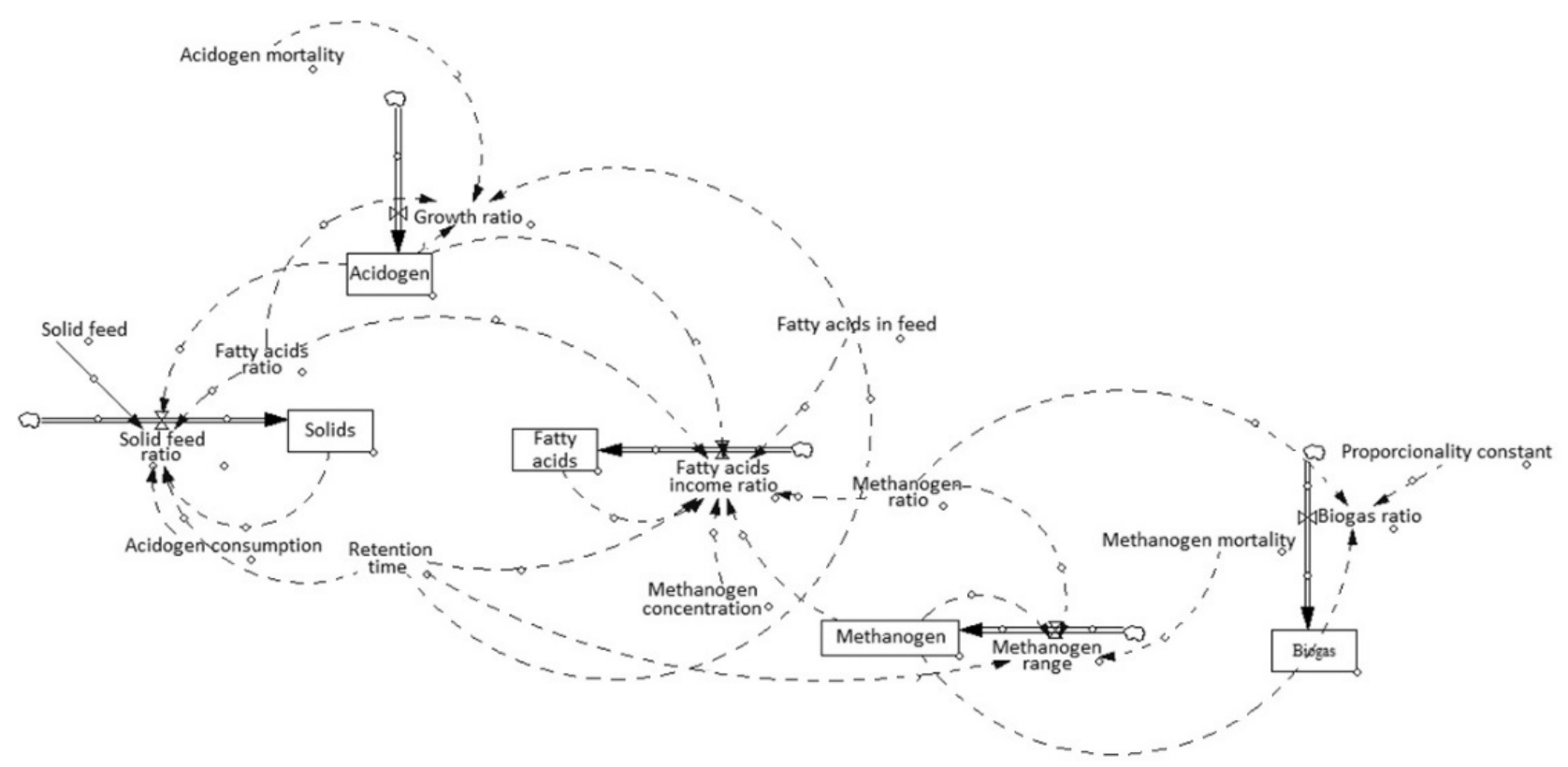

Fig. 1 Schematic representation of Vensim simulation.

size of a reactor as an independent result of the production ratio and the size of methanogen population determines the quantity of effective producers of biogas, there are the main factors to take into account in the case of analyze the behavior of biogas production system.

The retention time is a variable used directly in the process of simulation, but to rate the size and behavior of the microorganisms systems is necessary take into account the Monod model to simulate the concentration of microorganisms.

Fig. 2 shows the behavior of biogas production as a function of retention time and production time. In this case we can see a strong correlation between these parameters, due to it is a fundamental factor to produce a suitable environment with a high content of microorganisms.

The cause of this behavior is the time used for acidogen and methanogen bacteria to realize the process of microbial growth during the residence time in the reactor. In this case a low retention time is not adequate to the process due to then the bacterial culture is evacuated from the reactor before to complete an optimal growth cycle. By this reason the inclusion of Monod method is a fundamental

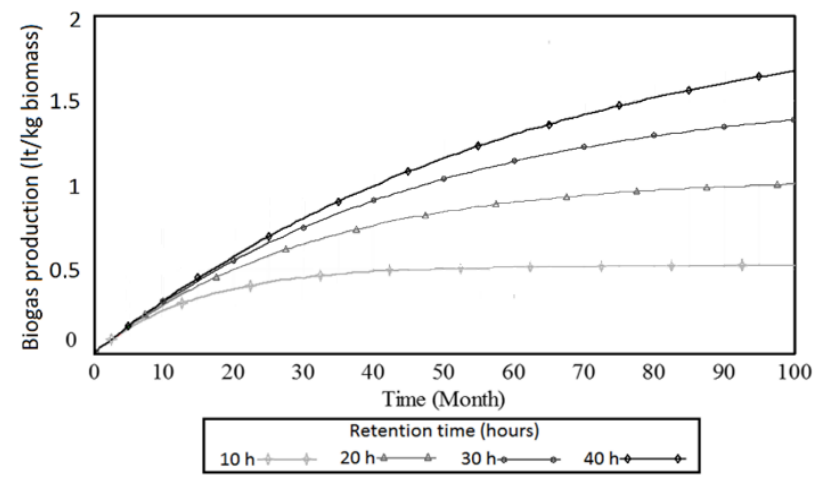

Fig. 2 Biogas production as a function of retention time.

parameter to determine the behavior of bacterial growth according to the residence time in the bio-digester.

In the case of retention time lower than $10 \mathrm{~h}$ is possible to see a rapid approximation to a constant parameter to biogas production due to the high removal of microorganisms from the process. It is due to for this retention time microorganisms are eliminated from the process before to complete the effective growth cycle.

In the other hand for retention time higher than $40 \mathrm{~h}$ the biogas production is higher than the same for 30 , 20 and $10 \mathrm{~h}$, but the additional increase in production is low for each increase in this variable, in this way the increase in production between $10 \mathrm{~h}$ and $20 \mathrm{~h}$ is 


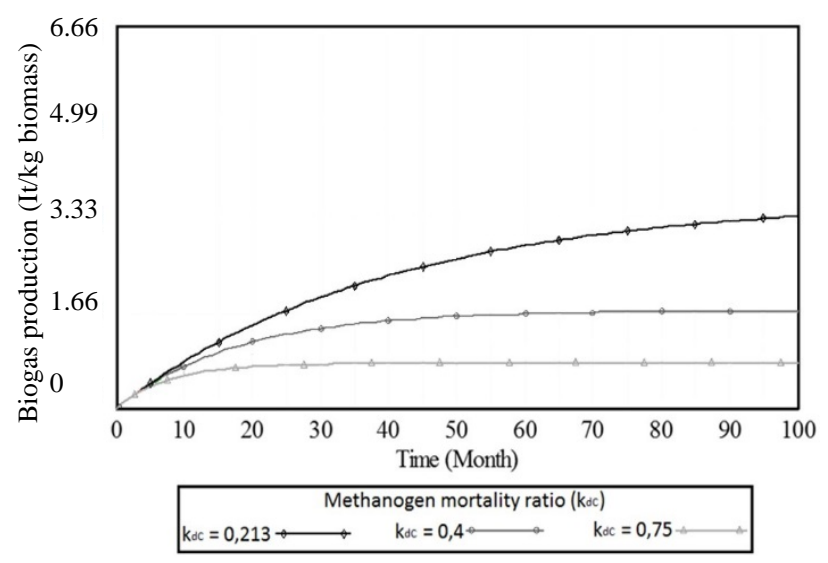

Fig. 3 Biogas production as a function of methanogen mortality ratio.

higher than the increase in production between 20 and $30 \mathrm{~h}$. By this reason a greater bio-digester is required for values of retention time higher than $40 \mathrm{~h}$ and the change in the yield of production is not significant.

To analyze the effect of another one main variable of the process, Fig. 3 shows the biogas production as a function of methanogen mortality ration and production time. In this case we can see a high dependence of the process in function of this variable, and it is due to this parameter is determining the concentration of microorganisms in the bio-digester, and due to biogas production is a direct function of the quantity of microorganisms in the reactor (assuming a total availability of organic waste), a high mortality ratio generates as a consequence a decrease in the biogas production.

For another hand, for a low methanogen mortality ratio is observed a high biogas production ratio due to methanogen bacteria population is increasing during the process. However, due to it is not a directly modifiable variable, it is necessary to select the microorganisms used in the process to choose those which have a low mortality ratio and establish a high control in the conditions of production environment such as avoid the presence of oxygen or sulfur. In this variable we cannot establish a low limit due to for lower values the production increases.

For each one of these cases we can see how the biogas production tends to a constant value due to along the time the bacterial growth and the microorganism population, due to addition and removal of solid waste, tends to a constant value.

\section{Conclusions}

Biogas production from solid organic wastes is a suitable option of energy production due to by this process a waste is approach to produce energy with low cost compared to others methods which includes the pre-production and treatment of raw materials. Another advantage is the low cost of the operative requirements due to operative conditions are near to normal conditions according to pressure and temperature.

In this case the main disadvantage is the recollection process of solid organic waste due to in most of the cases it is scattered as occurs in the case of animal waste and waste produced by human consumption. However this problem can be resolved by the inclusion of some practices such as the constant accumulation of waste in specific places before to be used to feed the bio-digester.

Among the main factors in biogas production systems, retention time and methanogen mortality ratio are more important due to these ones produce high variations in biogas production. According to it, the optimal conditions to obtain a high yield and decreasing the costs of production was selected.

A mortality ratio in methanogen and acidogenic bacteria lower than 0.2 is necessary to avoid a constant production along the time and to obtain a longer period of increase in quantity of production. A similar behavior occurs in the case of retention time due to for high values of this variable the production increases, but was determined $30 \mathrm{~h}$ as the time with the high efficiency due to for high values of it the relation of reactor price/biogas production increases as a result of a retention time with a high reduction in yield of production. In this case for these conditions was obtained a biomass production ratio of $3.33 \mathrm{~L}$ by each kilogram of biomass. 
In another hand, in the case of methanogen mortality ratio, this factor represents the demise of producing organisms and therefore the decreasing in biogas production. By this reason is necessary to ensure the optimal conditions to extend the life of microorganisms and carried out a selection of the main species methane-producing and due to it is an anaerobic process it is necessary to avoid the presence of oxygen and sulfur to decrease the mortality ratio of methanogen bacteria.

\section{Acknowledgements}

Special gratitude to the research group: Energy Recovery of Natural Resources-APRENA, Department of Chemistry from National University of Colombia for the contribution to this research.

\section{References}

[1] Contreras, A. I., Parra-Santiago, J., Sodré, J., Pathiyamattom, J., and Guerrero, F. C. 2014. "Transesterification Reaction of Waste Cooking Oil and Chicken Fat by Homogeneous Catalysis.” Journal of Chemical Engineering and Materials Science 8, In Press.

[2] Contreras, A. I., Parra, S. J., Sodré, J., Pathiyamattom, J., and Guerrero, F. C. 2014. "Biodiesel Production by Enzymatic Catalysis Process Using Two Analytical Ways: Gas Chromatography and Total Glycerol Determination.” Journal of Chemical Engineering and Materials Science 8, In Press.

[3] Mohra, S., Wangb, J., Ellemc, G., Wardd, J., and Giurco, D. "Projection of World Fossil Fuels by Country." Fuel 14, In Press.

[4] Contreras, A. I., Martínez, G. M., Figueroa, C. L., Parra, S. J., and Guerrero, F. C. 2014. "Modeling of Liquid-Liquid Extraction Process for Glycerol Purification from Biodiesel Production.” Journal of Chemical Engineering and Materials Science 10, In Press.

[5] Dincer, I. 2014. "Fossil Fuels and Alternatives."
Advanced Power Generation Systems 3: 95-141.

[6] Flescha, T., Desjardins, R., and Worth, D. 2011. "Fugitive Methane Emissions from an Agricultural Biodigester.” Biomass and Bioenergy 35: 3927-3935.

[7] Zamanzadeh, M., Parker, W., Verastegui, Y., and Neufeld, J. 2013. "Biokinetic and Molecular Studies of Methanogens in Phased Anaerobic Digestion Systems.” Bioresource Technology 149: 318-326.

[8] Kim, W. 2014. "Methanogens." Encyclopedia of Food Microbiology (Second Edition), 602-606.

[9] Borges, S., Bevilacqua, A., Magrini, G., and Borges, M. 2011. "Generation of Bioenergy and Biofertilizer on ASustainable Rural Property.” Biomass and Bioenergy 35:2608-2618.

[10] Schmidt, U., and Jordan, A. 2008. Report on the Biodigester User Survey 2008 Commissioned by the National BiodigesterProgramme, Phnom Penh.

[11] Billington, R. 1988. "A Review of the Kinetics of the Methanogenie Fermentation of Lignocellulosic Wastes.” Journal of Agricultural 39: 71-84.

[12] Chen, Y., and Hashimoto, A. 1978. "Kinetics of Methane Fermentation.” Biotech.8: 269-288.

[13] Hill, D. 1982. "Design of DigestionSystems for Methane Production.” Transactions of the ASAE 25:226-230.

[14] Hill, D. 1982. "Optimum Operational Design Criteria for Anaerobic Digestion of Animal Manure.” Transaction of the ASAE 25: 1029-1032.

[15] Hill, D. 1983. "Design Parameters and Operating Characteristics of Animal Waste Anaerobic Digestion Systems Wine and Poultry." Agricultural Waste 5: 157-178.

[16] Bala, B., and Satter, M. 1990. "Kinetic and Economic Considerations of Biogas Production Systems.” Biological Waste 34: 21-38.

[17] Hill, D. 1983. "Simplified Monod Kinetics of Methane Fermentation of Animal Wastes."Agricultural Waste 5: 1-16.

[18] Bala, B., and Satter, M. 1991. "System Dynamics Modelling and Simulation of Biogas Production Systems.” Renewable Energy 1: 723-728.

[19] Strigul, N., Dette, H., and Melas, V. 2009. “A Practical Guide for Optimal Designs of Experiments in the Monod model." Environmental Modelling \& Software 24: 1019-1026. 